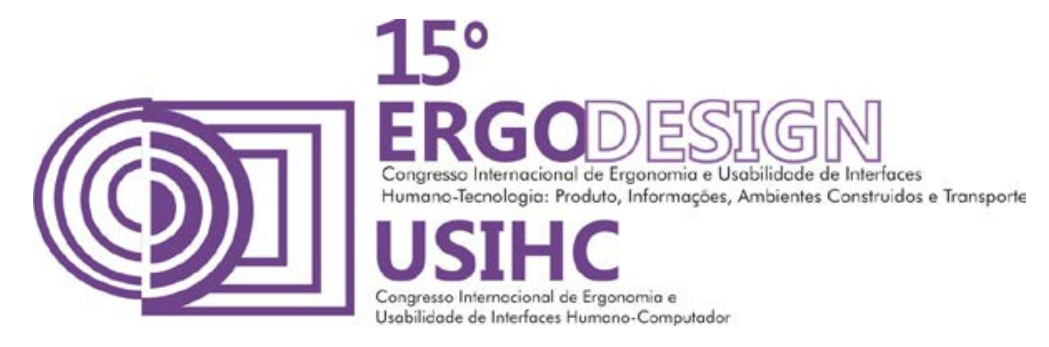

\title{
ERGONOMIA E INDÚSTRIA DE MADEIRA: UM ESTUDO DE CASO NO SETOR DE FABRICAÇÃO DE PORTAS
}

\author{
GONÇALVES, John (1) \\ BARROS, Bruno (2) \\ (1) Universidade Federal de Pernambuco, Bacharel \\ e-mail:johndesigner@outlook.com \\ (2) Universidade Federal de Pernambuco, Mestre \\ e-mail: barros bruno@hotmail.com
}

\begin{abstract}
RESUMO
O setor de moveis no Brasil vem crescendo a cada ano, e o aumento da competitividade advinda de empresas internacionais, o setor moveleiro brasileiro se mostra competitivo e para conseguir disputar com empresas do exterior, tem-se aumentado a produção, com aumento excessivo de horas extras, ocasionando lesões, afastamentos de funcionários por problemas se saúde. Onde esse trabalho partindo da metodologia de Intervenção Ergonomizadora do Sistema Humano-Tarefa-Máquina (SHTM), analisou e identificou problemas no posto de trabalho dos funcionários da empresa Madelar, e com os dados encontrados propor ideias para melhoria do ambiente de trabalho, assim favorecendo o bem estar dos trabalhadores.
\end{abstract}

\begin{abstract}
The furniture sector in Brazil is growing every year, and increased competitiveness arising from international companies, the Brazilian furniture sector shown competitive and achieve compete with foreign companies, has increased production, with excessive increase in hours extras, causing injuries, absences of employees for health problems. Where this work based on the Ergonomizadora Intervention methodology Human Task-Machine System (SHTM), analyzed and identified problems in the workplace of Madelar company employees, and our data suggest ideas for improving the working environment, thus promoting the welfare of workers.
\end{abstract}

\section{INTRODUÇÃO}

A marcenaria evoluiu da carpintaria, que na atualidade sofreu algumas mudanças, pois o profissional nesta área trabalha principalmente com madeiras nobres como: cedro, cerejeira, imbuia, mogno, marfim, ipê. Destas madeiras são fabricados os laminados e revestimentos 


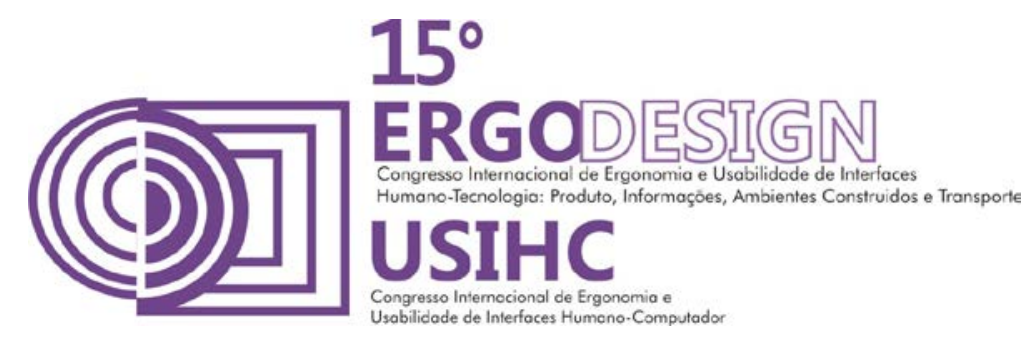

melamínicos utilizados nas mais diversas peças de mobiliário. Apesar de o marceneiro moderno fazer uso de máquinas para grande parte de seu trabalho, ele ainda faz uso da força manual na atividade, as quais, muitas vezes, são desempenhadas em postos de trabalho inadequados e improvisados.

Dentro deste contexto, a referente pesquisa foi realizada em uma empresa que está no mercado há 34 anos e conta com 110 funcionários contratados. O posto de trabalho selecionado foi o de Corte de Excedente de Portas e a pesquisa teve como objetivo a identificação e análise da postura dos funcionários ao exercer a atividade; locais que causem possíveis acidentes; sinalização do local e elementos de conforto ambiental, no intuito do desenvolvimento e correções projetuais do mesmo. Foram detectados problemas na postura dos funcionários, iluminação, sinalização, fabricação, e utilização dos equipamentos de proteção.

Com base teórica na antropometria e biomecânica ocupacional, foi possível identificar os limites do ser humano relacionados ao posto de trabalho. A obtenção das dimensões e proporções físicas do corpo humano, tabelas antropométricas facilitou a adequação dos produtos a seus usuários.

A interação física entre o trabalhador e seu local de trabalho, se caracterizou como uma atividade essencialmente estática, uma vez que há uma repetição dos movimentos com pouca alternância de músculos e uma concentração contínua de alguns músculos na atividade realizada no horário de trabalho.

Para o norteamento metodológico da pesquisa, selecionou-se algumas etapas da intervenção ergonomiazadora do sistema humano-tarefa-máquina. Desta forma, a apreciação ergonômica se revelou como uma fase exploratória que compreendeu o mapeamento dos problemas ergonômicos, efetuando observações e entrevistas nos locais de trabalho, registrando-os através de fotografias e vídeos e estabelecendo recomendações de melhoria.

\section{FUNDAMENTAÇÃO TEÓRICA}

\subsection{Identificação do Local de Trabalho}

A empresa onde se localiza o posto analisado trabalha com a fabricação de portas de madeira e chapas de MDF. O processo de fabricação das portas passa por várias etapas para chegar a expedição para ser vendida, elas são produzidas por encomendas nas medidas estipuladas pelos clientes. As etapas se dividem em corte, colagem, perfilagem, pintura, fitamento, montagem, embalagem e finalização. A pintura das partes externas das portas é feita em quatro etapas, são quatro máquinas por onde passam as portas que serão pintadas, cada máquina com uma tonalidade de tinta distinta da outra, pintura feita em UV. A segunda etapa, a etapa de montagem da estrutura interna das portas, onde é preenchida com os sarrafos internos, e é feito a pintura das laterais das portas. É feito o corte dos sarrafos e das laterais para ficar nas dimensões das portas. Depois de ser feito o corte dos excessos, ela vai para essa máquina onde é verificado se existe algum defeito, caso não tenha é levada para outra etapa, a finalização caso aja algum defeito ela vai para raspagem manual e daí para finalização. Na etapa de finalização, é feito os detalhes das portas as molduras feito a talhação, frisamento, desenhos das portas, e é colocado as dobradiças e feito o furo onde será acoplado 


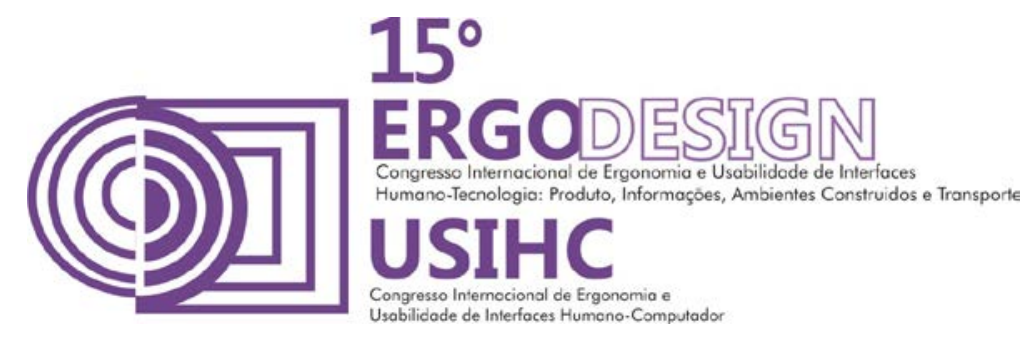

a fechadura da porta. Como se vê, a empresa é dotada de muitos postos de trabalho de diferentes funções e atividades desenvolvidas. O local selecionado para análise foi a etapa onde é feito o corte dos excessos das portas, como pode ser visto na (figura 1).

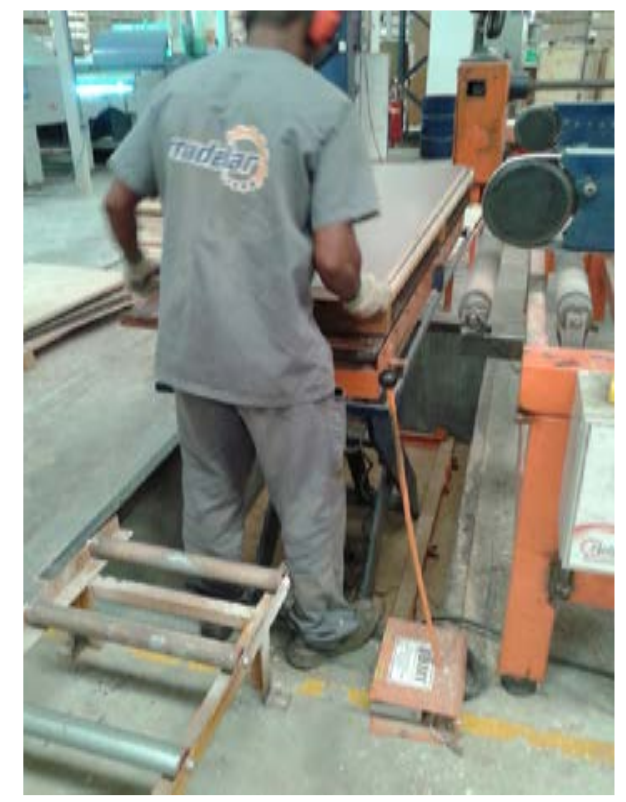

Figura 1: Posto de trabalho analisado

De imediato viu-se que, no posto, o operador passa toda a jornada de trabalho na posição de pé, próximo a uma abertura no piso por conta do ajuste do equipamento, podendo ter o pé preso, esmagado, ou até cair dentro desse espaço. Viu-se também que o usuário não faz utilização de máscara de proteção, mesmo ciente da excessiva poeira de madeira resultante do corte da madeira realizado na máquina. Também ficou evidente a sinalização inadequada próxima do local; a pouca iluminação; o calor excessivo; elevada incidência de ruído; extintores fora do local adequado e pouco espaço para locomoção para realização da sua função.

\subsection{Dados Antropométricos e Biomecânicos}

Os estudos realizados pela antropometria facilitam o uso dos produtos pelos seus respectivos usuários se adequando as suas limitações físicas e evitando se causar lesões. Tomando como base o estudo do local de trabalho da empresa, assim procurando evitar possíveis lesões e o desconforto ao exercer suas respectivas funções pelos funcionários que trabalham em uma longa jornada de trabalho. Ela auxilia na conformação da pega, então para se projetar tem que se pensar na pega do usuário, na postura do usuário ao utilizar o produto, controles e o mecanismo, espaçamento entre o produto e o corpo. Se preocupando com idade, sexo e capacidade física estatura entre outros.

De acordo lida (2005) a Antropometria trata das medidas físicas do corpo humano, e aparentemente, medir as pessoas seria tarefa fácil, bastando para isso ter uma régua, trena, e 


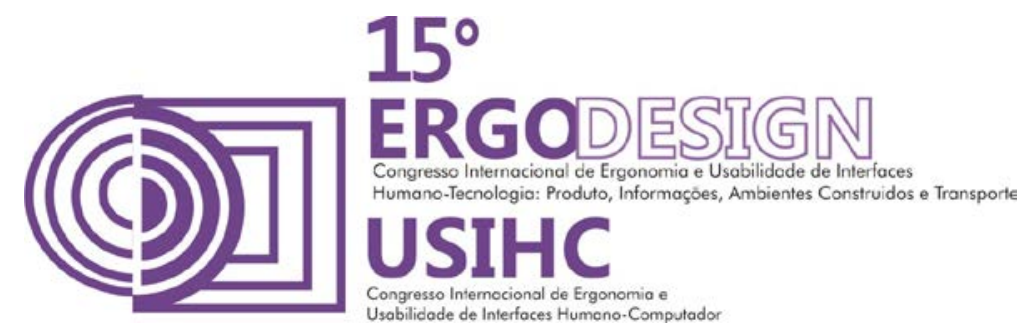

balança. Entretanto, isso não é tão simples assim, quando se pretende obter medidas representativas e confiáveis dos mais variados tipos e dimensões.

O autor também afirma que o trabalho estático é aquele que exige uma contração contínua dos grupos musculares que estão sendo contraídos, para manter uma determinada posição. lida (idem) alerta que um trabalho estático com aplicação de $50 \%$ da força máxima pode durar no máximo 1 minuto, enquanto que aplicações com menos de 20\% da força máxima permitem manter as contrações musculares por mais tempo e que após ultrapassar os 15\% da capacidade máxima de desempenho da musculatura humana, deverá haver pausas para recuperação dessa musculatura e com isso o trabalhador continuar desenvolver sua atividade.

Como o trabalho realizado é classificado como estático, em uma jornada de trabalho de 8 horas ele oferece grandes riscos de incidência de DORT'S. A sigla DORTs dignifica Distúrbios Osteomusculares Relacionados ao Trabalho, segundo (Hales e Bernand,1996) as DORTs são distúrbios dos tecidos moles e suas estruturas ao redor (Músculos, ligamentos, nervos e tendões), incluindo também a LER Lesões por esforço repetitivo e LTC Lesões por traumas cumulativos. De acordo com dados do Instituto Nacional de Prevenção às LER/DORT'S. (http:/www2.uol.com.br/prevler/), estas são a segunda causa de afastamento do trabalho no Brasil.

As DORTs são causadas por esforços repetitivos onde não há pausas para descaço, má postura ao exercer uma determinada função, excesso de carga, ficar em uma mesma posição durante um longo período de tempo. No posto de trabalho analisado, identificamos os riscos de ocorrência de alguns tipos de DORT'S. Devido também ao funcionário trabalhar com variações de altura da sua bancada, onde ela só atende em certos momentos a altura desejada para 0 trabalho, como podemos ver na (figura 2) as dimensões ideais para cada atividade, trabalhos de precisão, trabalhos leves e pesados exigem alturas fixas para assim proporcionar uma melhor visibilidade, melhor pega, evitando posições erradas.

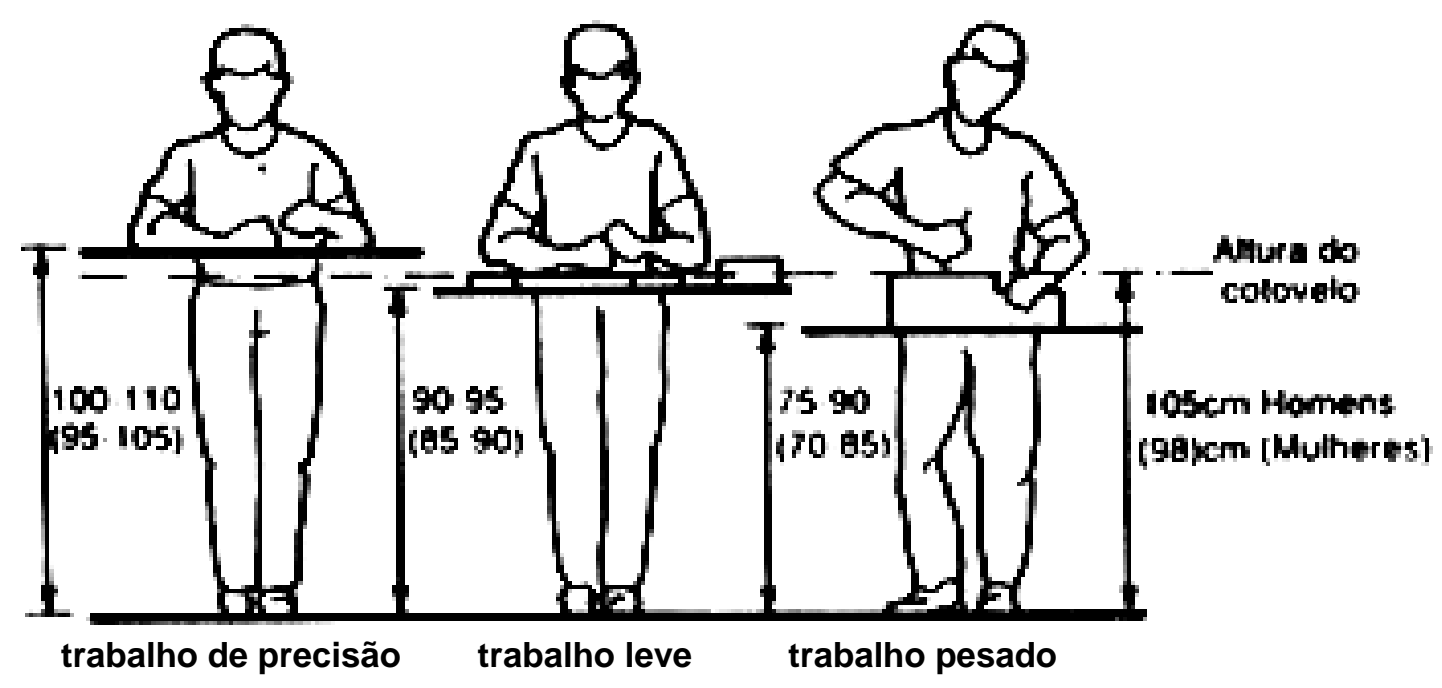

Figura 2: Alturas recomendadas para superfícies horizontais de trabalho na posição de pé, de acordo com o tipo de tarefa. (GRANDJEAN, 2005). 


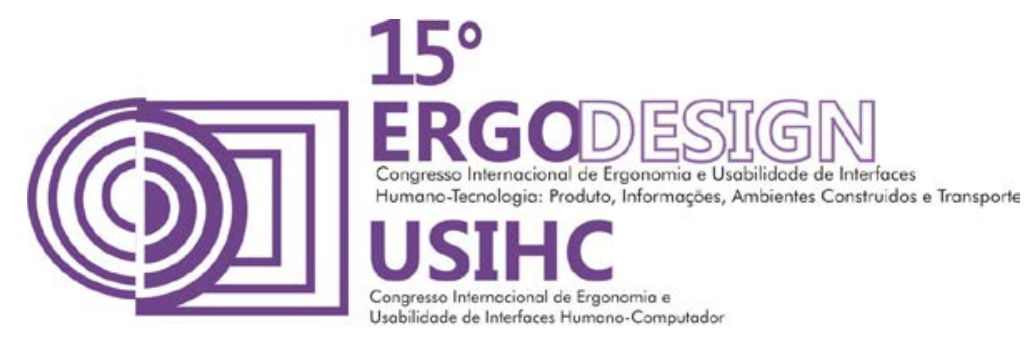

Onde a primeira lesão observada foi a Síndrome do Ombro Dolorido, identificada através da atividade com membros superiores acima do nível dos ombros. O funcionário alegou dores na região do deltoide e na articulação do ombro, o que nos fez atentar para um estudo do redimensionamento do posto de trabalho.

Também identificamos a incidência de bolhas e calosidades, devido ao atrito constante e pressão em pontos específicos da pele do operador. O usuário apresentou formação líquida subcutânea e camadas densas e secas na pele das mãos, o que nos fez atentar para um estudo da melhor distribuição da carga sobre a superfície da mão, assim como um aumento de tração.

Outro risco de DORT identificado foi o da a Síndrome do Túnel do Carpo, causada pela pressão repetitiva e stress sobre os tendões, especialmente se as mãos se inclinam na altura do punho. Os sintomas identificados, os quais levaram a eleição deste risco foram a dor, formigamento e insensibilidade causados pela pressão da bainha do tendão inchado sobre 0 nervo medial. O risco desta DORT nos fez atentar para a relevância de ferramentas e estruturas de trabalho que possam ser usadas com as mãos na posição neutra.

Percebemos ainda a risco de Distensões, causado pelo estresse excessivo decorrente da repentina combinação de força e má postura realizada pelo funcionário. A dor alegada pelo funcionário nos fez atentar para um estudo da redução da necessidade de movimento brusco, assim como um design que melhore a pega e a postura.

Por fim, identificamos o risco de Deformação nas Articulações, causado pela repetição de atividade estressante por um longo período de tempo. A redução da flexibilidade ressaltada pelo usuário nos fez atentar para um estudo e especificação de ferramentas/máquinas que possam ser usadas em posição de conforto.

\section{PROCEDIMENTOS METODOLÓGICOS ADOTADOS}

Metodologia selecionada para o desenvolvimento do estudo foi a Metodologia de Intervenção Ergonomizadora do Sistema Humano - Tarefa - Máquina, desenvolvida por Moraes e Mont'Alvão (2010). Algumas etapas da metodologia foram elencadas e guiaram todo o estudo para o estabelecimento de recomendações ergonômicas de reformulação do posto de trabalho estudado.

\subsection{Apreciação ergonômica}

A apreciação ergonômica é uma fase de mapeamento dos problemas ergonômicos da empresa. Nesta fase é feita a sistematização do sistema humano-tarefa-máquina e a delimitação dos problemas. Esta fase é de observações, entrevistas e registros dos operadores no seu local de trabalho, e termina com o parecer ergonômico, que é a apresentação ilustrada dos problemas e disfunções do sistema humano-tarefa-máquina.

\section{- Sistematização do sistema Humano-Máquina}

a. Identificação do sistema-alvo 


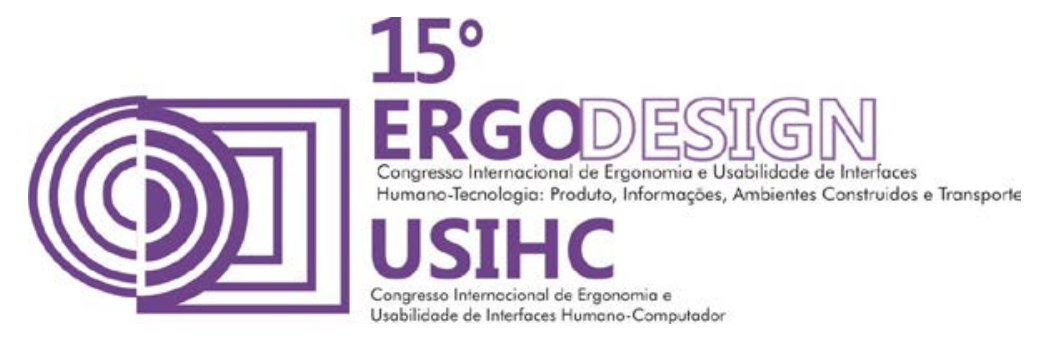

Para a realização deste projeto o sistema alvo é o local de trabalho da empresa Madelar, que se divide em etapas que começa no setor de corte, e vem colagem, perfilagem, pintura, fitamento, frisamento e embalagem. Onde os funcionários trabalham 8 horas diárias dividindo em três turnos, o horário do turno avaliado é de 06:00 da manhã ás 14:00 da tarde de segunda a sexta.

b. Caracterização e posição serial do sistema

A figura 2 abaixo representa a posição do serial do sistema- alvo que é o local de trabalho, para a compreensão das relações entre o sistema- alvo em questão.

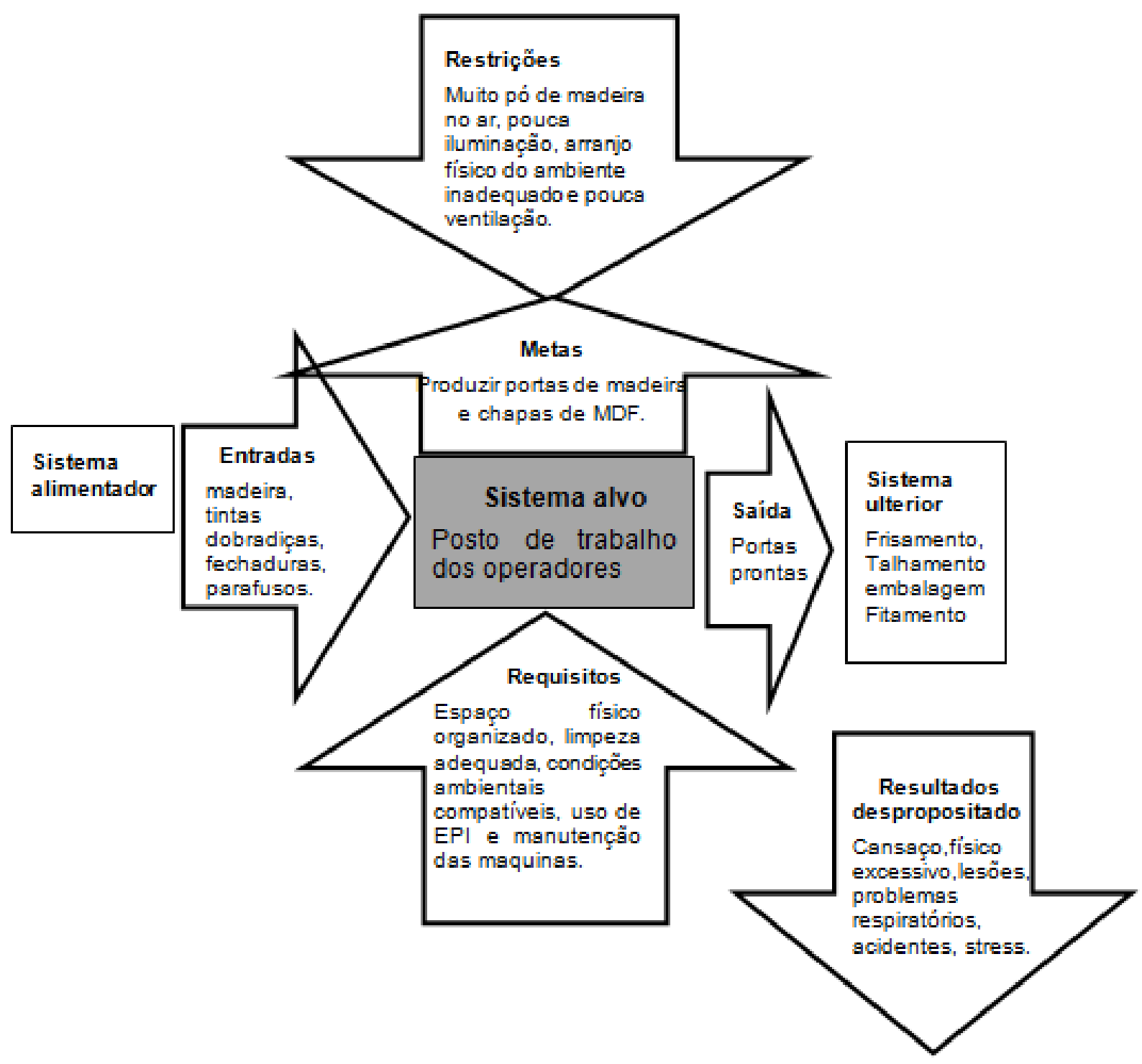

Figura 3: Caracterização e posição serial do sistema 


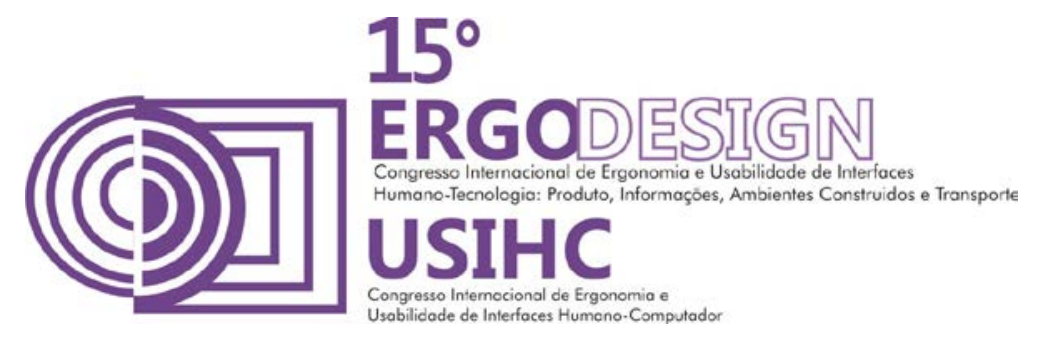

c. Modelagem comunicacional do sistema

A figura 3 abaixo apresenta as sequências das funções/operações e as decisões implicadas que compreendem os sentidos humanos envolvidos, ações realizadas, deslocamentos, postura, informações que a máquina fornece para o ser humano processar.

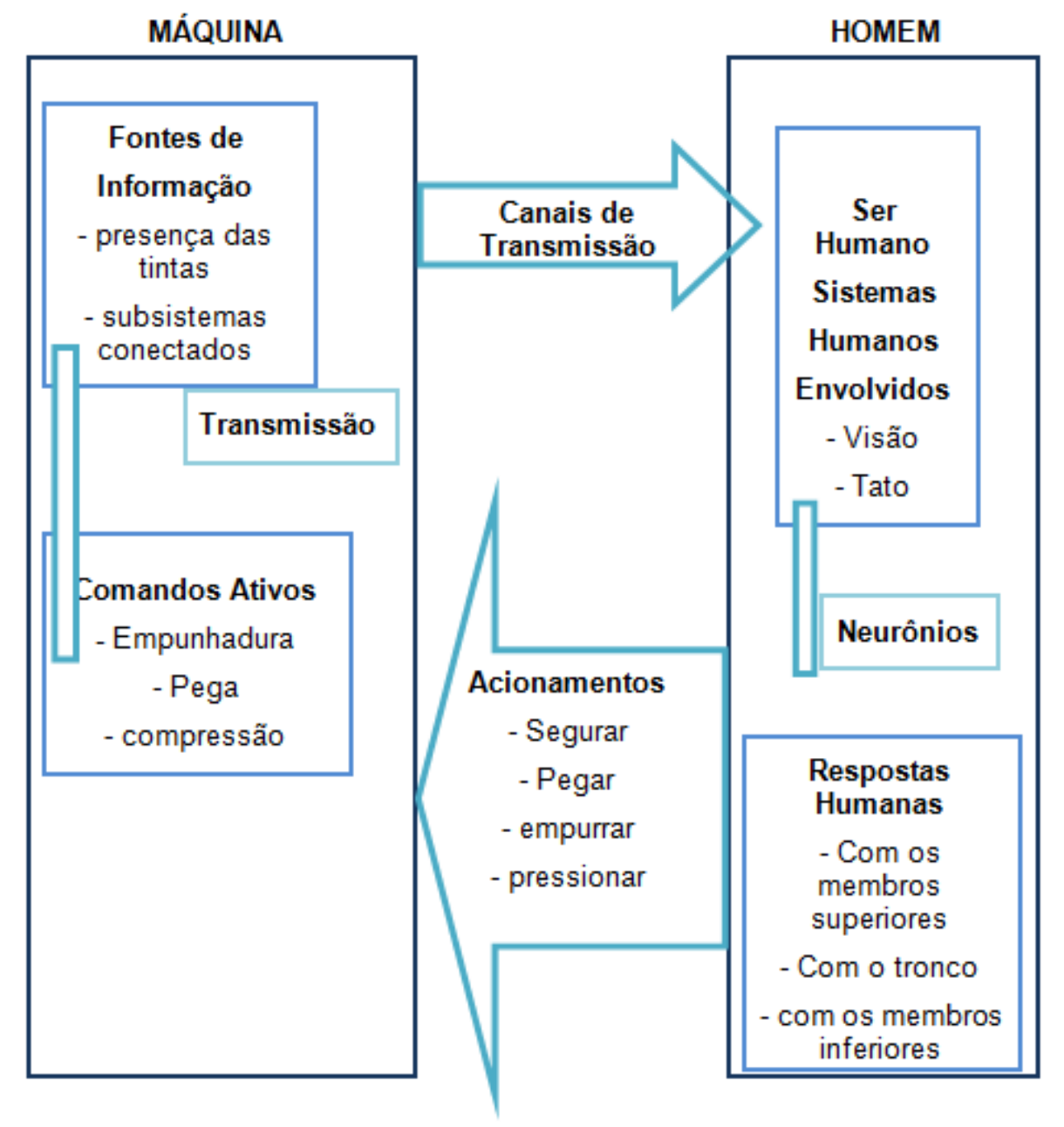

Figura 4: modelagem comunicacional do sistema

\subsection{Aplicação De Questionário}

Foi necessária a aplicação de um questionário ao funcionário, para a identificação de elementos perceptivos. A pesquisa foi dividida em quatros partes: Agentes Contribuintes, Agentes Fisiológicos, Agentes Ambientais e Agentes Psicossociais. Primeira parte são dados pessoais, como idade, peso, estado civil, local onde mora, entre outros. A segunda parte 


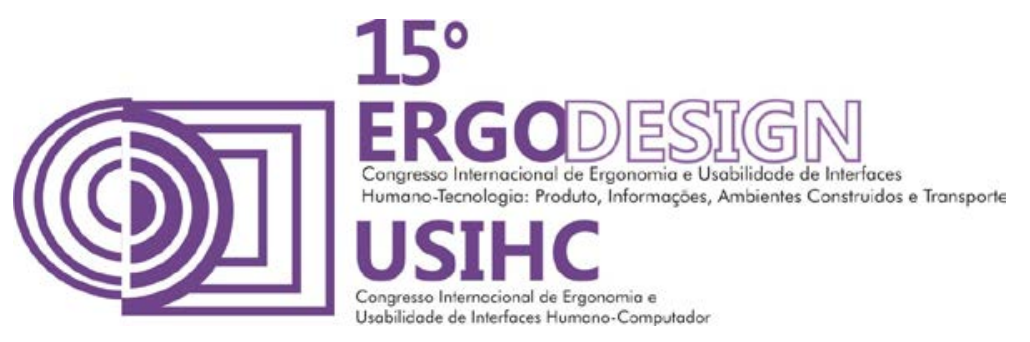

corresponde a perguntas sobre as condições físicas do respondente, como doenças, medicamentos, dores, desconforto. A terceira parte possui questões onde aborda os equipamentos em ambiente de trabalho, como opinião sobre o mobiliário e o próprio ambiente de trabalho. E a última parte traz perguntas sobre o ambiente organizacional no trabalho, como satisfação com a escala de trabalho, se tem passado por problemas ultimamente.

Dentre os questionamentos sobre as condições físicas, foi solicitado que o funcionário informasse se havia dores musculares, irritações, lesões, fadiga e cansaço, bem como a última vez que ele adoeceu e se normalmente costumam tomar algum tipo de medicamento para aliviar esses problemas de lesões e fadigas.

Em que partes do corpo incomodavam mais e em que quantidade de tempo que isso ocorria ao carregar o pulverizador. Pedimos que descrevesse sobre as sensações como acordar cansado, com dores ou ficar irritado.

Foi questionado se os entrevistados estavam satisfeitos com seu trabalho como definiria seu relacionamento com o dono da empresa e colegas. Esses questionários foram necessários para saber se o entrevistado estaria sofrendo tipo de algum trauma resultante do trabalho estático.

\subsection{Aplicação da Escala de Corllet}

A escala de Corlett, chamado também de Diagrama das áreas dolorosas, consiste em dividir 24 segmentos no corpo humano, em cada segmento estariam localizadas as áreas onde os trabalhadores sentem dores. É feito análise entrevistando a partir desse diagrama se o há no trabalhador do início ao fim do trabalho, realizando assim um comparativo para que sejam apontadas as regiões onde os trabalhadores sentem dores.

A partir de uma escala é realizado essa avaliação, onde segundo o autor lida se pede para que o trabalhador possa apontar o nível de desconforto em que eles sentem em cada segmento, onde essas dores são classificadas em níveis. Esses níveis são contados em de 0 a 7 , sendo nível zero para "sem desconforto" até o sete "extremamente desconfortável".

Esse Escala de Corllet foi bastante útil para que no processo de análises dos resultados, fosse possível ver que a grande maioria das dores e desconfortos corporais, estava relacionada ao mau uso do pulverizador e que poderia ser analisado de uma forma correta resultando numa proposta de um produto mais ergonômico, para a melhoria da vida do usuário em seu ambiente de trabalho.

\section{RESULTADOS}

\subsection{Questionário}

Foi entrevistado um funcionário, com idade de 26 anos. Pesando $68 \mathrm{~kg}$, e estatura de 1,70. Sendo ele solteiro e no momento da entrevista se encontrava solteiro, não tinha filhos, sexo masculino e destro. O funcionário mora na mesma cidade da empresa e relatou que gasta em média de 10 a 30 minutos para chegar ao trabalho. Afirmou ainda que está trabalhando nesse emprego há 1 ano, tendo uma jornada de trabalho de 8 horas diárias, mas as vezes realiza 9 horas diárias. 


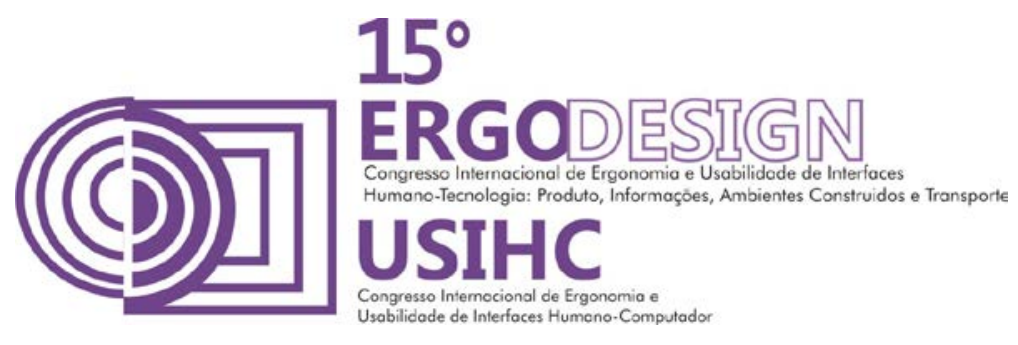

O funcionário afirmou que não está fazendo uso de nenhum medicamento para dor, e nos últimos dias não teve nenhum tipo de doença, nunca deixou de realizar suas funções por causa de incômodos, e nos últimos 30 dias relatou dores nos ombros e costas na região superior, inferior e médio, punho direito e esquerdo. As cinco regiões que mais sente dor ficam assim classificadas: 1) punhos, 2) ombros, 3) costas, 4) cabeça e 5) joelhos. Foi perguntado a respeito do local onde trabalham, relacionado altura dos equipamentos, largura, conforto entre outras e a altura foi o mais criticado, por terem variações de altura os equipamentos na sua maioria não atende a essas variações. O espaço disponível foi outro fator relatado o qual atrapalha muito na realização de suas funções.

O entrevistado avaliou a iluminação, ruído, temperatura, cores do ambiente, ventilação e o odor como sendo de ruim a muito ruim, onde só as cores do ambiente foram avaliadas por como regular. Apesar dos itens avaliados, o funcionário se sente satisfeito com sua carga horária, com o salário e consideram a relação com o chefe e colegas de trabalho de bom a muito bom.

\subsection{Mapa de Desconforto Postural Corllet}

Este mapeamento consistiu na avaliação das dores causadas pelo período de trabalho 8 horas nas suas respectivas funções. O questionamento foi aplicado a 1 (um) funcionário em 3 (três) horários distintos. A primeira aplicação foi às 6:00 (seis) horas da manhã, antes do início das atividades proporcionando a avaliação em repouso e as dores resultantes das atividades presentes exercidas onde houve a existência de dores nos punhos, joelho direito, ombro direito e costas.

A segunda aplicação iniciou-se às 09:30 (nove e trinta) horas da manhã onde o entrevistado após realizar três horas e meia trabalhadas se queixou de dores de nível moderado nas regiões dos punhos, ombros, joelhos e pernas.

A terceira avaliação iniciou-se às 14:00 (quatorze) horas da tarde que é o horário de finalização da jornada de trabalho visto que é um longo período, foram detectadas nesta última avaliação dores de nível insuportáveis na região dos punhos, costas e ombros. Levando em consideração que o funcionário permanece em pé durante toda jornada de trabalho, realizando operações que exige posturas inadequadas dos membros superiores e inferiores e da região das costas.

\subsection{Problematização Ergonômica}

Através da análise foi percebido que o funcionário ao longo do horário de trabalho está propício às possíveis lesões por esforço repetitivo e lesões que podem ser ocasionadas pela falta de proteção nas máquinas, pela não utilização de equipamentos de proteção individual e equipamentos de proteção coletiva, sinalização precária, ambientes de risco para os funcionários.

Saltaram aos olhos a alta frequência com que atividades com membros superiores em alturas acima do ombro são realizadas, levando ao risco de incidência de bursite. Assim como atividades deste membro em alturas muito baixas, o que pode causar lesões na coluna vertebral e na região dorsal e pescoço. Também identificamos um problema acidental, com a exposição à abertura que fica no equipamento (próximo das pernas), assim como problemas acionais, por conta das más posturas decorrentes das empunhaduras. Ainda ficaram evidentes 


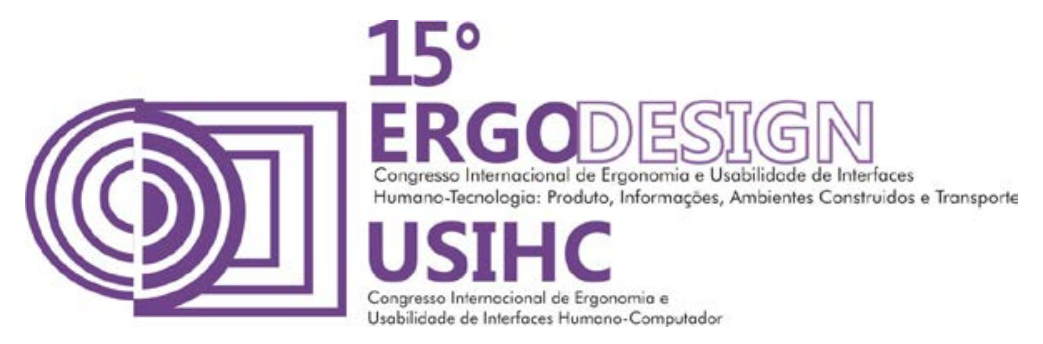

problemas movimentacionais e acidentários, por falta de dispositivos de proteção nas máquinas e instrumentais por falta de arranjo físico adequado. Na (figura 3) que se segue, observamos em A um problema acidentário e em B Movimentacionais.

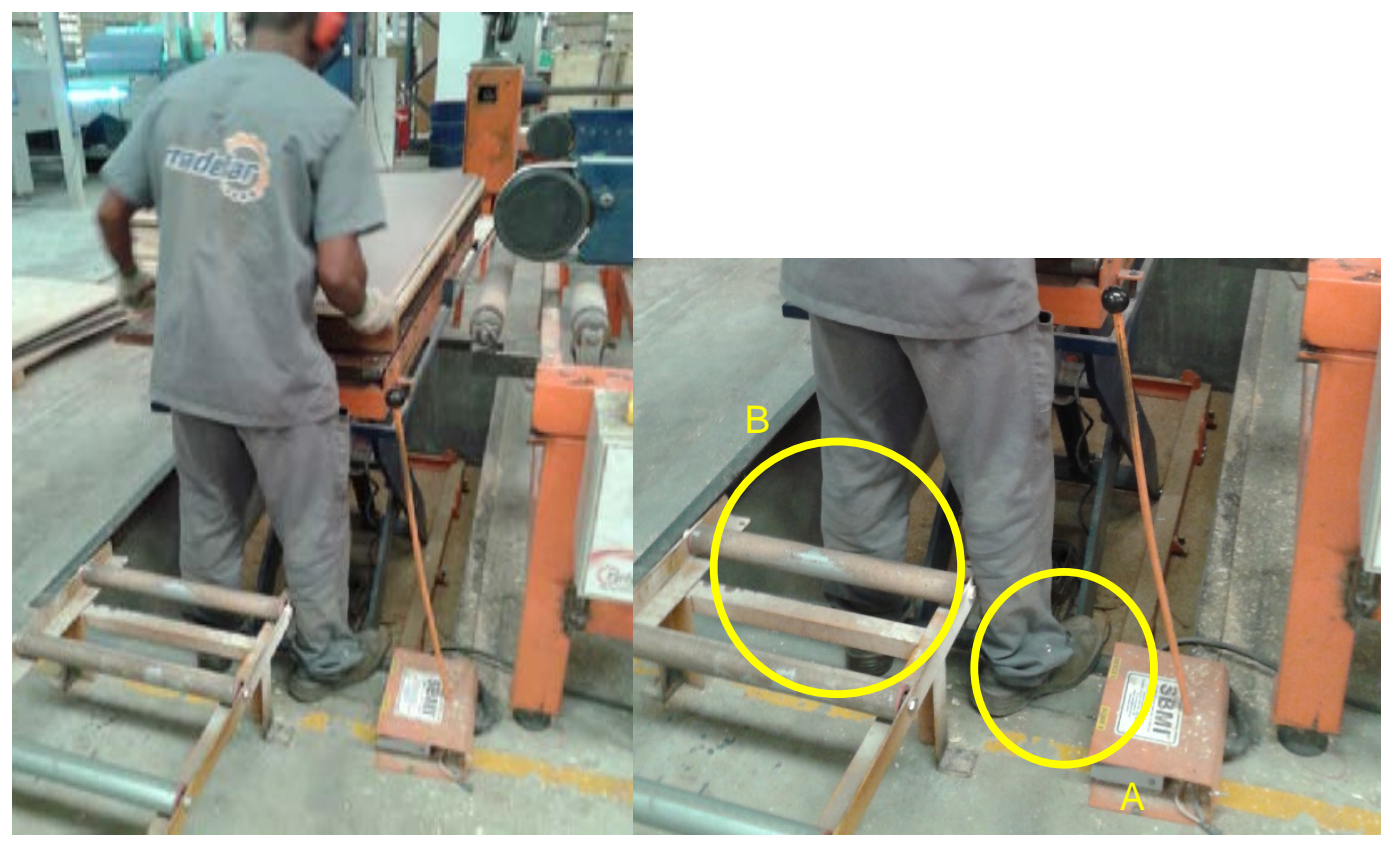

Figura 3: problematização ergonômica

\subsection{Lista de recomendações ergonômicas:}

- Uso de máscara de proteção pelo funcionário;

- Melhoria na sinalização, layouts.

- Revitalização do piso onde encontram-se buracos;

- Aberturas nas laterias no galpão da fábrica para circulação do ar;

- Alteração das bancadas e carrinhos para atender a altura dos funcinários, que tenham um regulador de altura pois nem todos possuem;

- Melhor organização do local de trabalho, organização das etapas de produção;

- Manutenção periódica dos equipamentos;

- Adequação da iluminação, criação de acessos para entrada da luz.

\section{CONCLUSÕES E CONSIDERAÇÕES FINAIS}

Depois de várias análises feitas, utilizando a Metodologia de Intervenção Ergonomizadora do Sistema Humano - Tarefa - Máquina, desenvolvida por Moraes e Mont'Alvão (2010) foi concluído que o local de trabalho deverá passar por mudanças que irá ajudar os operadores na realização da sua função e que afetam o bem estar dos mesmos.

Muitas falhas, até então não visualizadas pelo sistema gestor da fábrica, foram apontadas, tais 


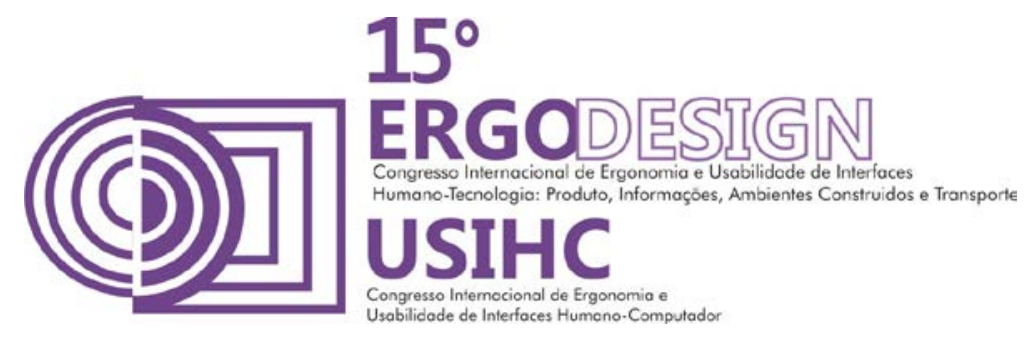

como a inadequação da iluminação e aeração, poeira, falta de sinalização, não utilização de equipamentos de proteção, ruídos e máquinas que não atendem as necessidades dos usuários.

As aplicações de questionário ajudaram a conhecer o local do trabalho, suas atividades e identificar os erros mais graves que estão perceptíveis. Conseguiu-se identificar que o local está inadequado em alguns aspectos para esse tipo de atividade que é realizada, não fornecendo a segurança necessária para o trabalhador. Foi possível conhecer melhor os funcionários e os problemas já causados por essa atividade.

O foco da pesquisa foi fazer com que os proprietários da empresa, chefes e responsáveis vejam os respectivos problemas e os elimine, tornando o ambiente um lugar adequado para os funcionários, evitando afastamentos por lesões, acidentes de trabalho que causem possíveis perdas e até mortes dos mesmos.

\section{REFERÊNCIAS BIBLIOGRÁFICA}

ASSOCIAÇÃO BRASILEIRA DE NORMAS TÉCNICAS - NBR 10152: níveis de ruído para conforto acústico. Rio de Janeiro, 1987.4 p.

BRASIL. Fundacentro. Ruído. Disponível em: http://www.fundacentro.gov.br. Acesso em: 15/01/2015.

CONSELHO E SEGURANÇA DO TRABALHO. O que é vibração? 2011. disponível em: http://conselhoeseguranca.blogspot.com.br. Acesso em: 17/01/2015.

DUL. Jan. Ergonomia prática 1954. Editora Blucher 2 edição, tradutor Itiro lida 2004.

FILHO. João Gomes. Ergonomia do objeto: sistema técnico de leitura ergonômica.

GRANDJEAN, E. Manual de Ergonomia: Adaptando o trabalho ao homem. 5.ed. Porto Alegre: Artes Médicas, 2005.

IIDA, Itiro. Egonomia: projeto e produção. 2a edição. São Paulo: Edgard Blucher, 2005.

LAMBERT, Roberto, DUTRA, Luciano, PEREIRA, Fernando O. R. Eficiência Energética na Arquitetura. São Paulo: PW, 1997.

Ler/DORT. Cuidados para a sua saúde. Disponível em <http://www.lerdort.com.br>Acesso em 16/01/2015.

MORAES, Anamaria; MONT'ALVÃO, Cláudia. Ergonomia: Conceitos e aplicações. Rio de Janeiro: 2AB, 2010.

NORMA ISO 11064-6:2005 Disponível em: http://www.iso.org/iso/catalogue detail.htm?csnumber=39713. Acessado em 16/01/201.

VILLAROUCO, V. O ambiente está adequado? Anais do ENEAC 2007: I Encontro Nacional de Ergonomia do Ambiente Construído e II Seminário Brasileiro de Acessibilidade Integral. Recife, 2007. 